\title{
Anthropometric Factors And Physical Condition Dominant Determining Overhead Throws And Batting Skills In Softball
}

\author{
$1^{\text {st }}$ Arif Eka Saraya \\ Pascasarjana \\ University Sebelas Maret \\ Surakarta, Indonesia \\ arifekasaraya55@gmail.com
}

\author{
$2^{\text {nd }}$ Sugiyanto \\ Pascasarjana \\ University Sebelas Maret \\ Surakarta, Indonesia \\ arifekasaraya55@gmail.com
}

\author{
$3^{\text {rd }}$ Muchsin Doewes \\ Pascasarjana \\ University Sebelas Maret \\ Surakarta, Indonesia \\ arifekasaraya55@gmail.com
}

\begin{abstract}
Anthropometric factors and physical condition, among others, height, arm length, arm muscle strength, hand-eye coordination, balance, and reaction time. This research goal is to determine the anthropometric factors and the physical condition of the dominant determinant of overhead throws and batting skills in softball. This research approach uses a quantitative to design of confirmatory factor analysis. This research population is training student achievement softball in Sports Education University of Riau. A sample of 100 people was obtained through a proportional random sampling technique. The data used are taken through a series of tests of the independent and dependent variables. This research method through testing confirmatory factor KMO and Bartlett's Test analysis using SPSS Results from this research is: factor of Anthropometry and dominant physical condition determinants is arm length with value 0,818 , arm muscle power with value 0,751 , hand eye coordination with value 0,837 and balance with value 0,775 . The conclusion of this research is: the factor of Anthropometry and dominant physical condition determinants overhead throws skill and batting skill in game of softball is arm length, the arm muscle power, the hand eye coordination and balance. While the factors not determine is height and reaction time.
\end{abstract}

Keywords — anthropometri factor, physical condition, overhead throw, batting skill

\section{INTRODUCTION}

Softball is a small ball game born in the United States created by George Hancock in the city of Chicago in 1887. Softball in Indonesia is often called softball. Softball is the development of similar sports such as baseball or hardball. Although at first glance looks the same but softball and baseball have some pretty basic differences, the difference is baseball is only played by men. So sometimes baseball is also called hardball, while softball can be played by men and women. The softball ball is also a few inches bigger than a baseball ball. Softball is played by two squads with each team consisting of 9 players consisting of 7 inning [4]. By collecting numbers from hitting the ball. The start of the game begins with a pitcher (throw), by throwing a ball with a spin to the batter using a bat. The two teams are one of the defensive and the other becomes the offense team each competes to collect the numbers by spinning the three base runners must touch each base until it returns to the home plate, the batter can return to home plate with survived to get one [5].

The success of coaching improves the softball skills especially throwing and batting requires various supporting components. Physical condition is one of the factors that determine performance or appearance, so the collapse of physical condition will lead to loss of skills [2].

Coaching physical conditions in sports that if an athlete wants to perform must have physical conditions such as: strength, endurance, muscular power, speed, coordination, flexibility, agility, balance, accuracy, reaction. Based on the physical condition component a softball athlete must know what components of physical condition affect their basic engineering skills especially on top-throwing and hitting techniques such as strength, muscle explosive power, coordination, precision, and reaction [2].

Be advised that papers in a technically unsuitable form will be returned for retyping. After returned the manuscript must be appropriately modified. How could a bat be able to hit the ball well if he lacked strength, good arm muscle power. So the result will not be able to bounce so far out of the field. If the blow is weak then the ball will be easily anticipated by the opposing player so he will easily be turned off before reaching the base. Then hand eye coordination and reactions in swinging the bat are also indispensable for a batter to be able to determine when the time is right for him to hit the ball thrown by the pitcher.

In the upper throw there are also some physical conditions that may affect the throwing of such softball athletes as arm muscle explosiveness, hand eye coordination, and precision are needed to produce precise and accurate throws. If a softball player does not have good muscular explosive power then the result will not have enough speed to turn off the runner going to the base. Accuracy is also required in this case so that the throw in the produce does not deviate from the target so it will not be difficult for his team mates to catch the 
ball. Because if the throw does not have speed and accuracy, then the runner will very easily advance to the next base safely. However, if you have a throwing speed and a good accuracy it will be very easy in turning off opponent runners. In addition, every player in the team must also have the ability of the physical condition in order to make the right throw and quickly to turn off the other runners before reaching the base point.

However, anatomical physical factors should also not be ignored. The anatomical factor or commonly said as a posture also provides its own advantages in sports. The selection of athletes to pursue a sport is not independent of these factors. The ideal body shape in accordance with the exercise is one of the conditions that can affect the achievement of sport. [1] states "One aspect to achieve achievement in sports is a biological aspect that includes the structure and posture that is the height and length of limbs, large size, width and weight, and somatotype (body shape) ". A comparison of the length of the body parts to the height of each of these animals or briefly is called the anthropometric size ratio, which can provide relative value for each individual that can be compared with other individuals. Different height and arm factors can affect the outcome of the throwing and hitting skills of each individual in the softball game.

\section{MATERIALS AND METHODS}

This research was conducted on campus of University of Riau Sports Education and Venue Softball Rumbai. The sampling technique using proportional random sampling is the method of sampling from the population with random, so that each member of the population is entitled to be a sample. The sample in this research is some of the students in sport education of University of Riau who have never followed softball recovery amounted to 100 people.

The method used in this research is correlational research with confirmatory factor analysis design that is confirm the correlation of indicator variable with latent variable that determine skill upper skill and skill hit on softball. The collected data is then verified and tabulated to be quantitatively processed by: multivariate statistical factor analysis using SPSS computerized software so that it can be reduced to several factors only. Calculates the average donation value of each factor on the latent variable and the dependent variable. Describes the value and position of the average score of the dominant variable in the transformation of the importance-performance matrix.

The data analysis used in this research is Confirmatory Factor Analysis Technique which is a factor analysis technique which a priori based on known and predetermined theories and concepts [1]. The data will be processed using computerized statistic program with SPSS (Statistical Product and Service Solutions). According to [3] the confirmatory factor analysis technique is exactly the same as the exploratory factor analysis technique by calculating the loading factor or the coefficient of factor or lamda value $(\lambda i)$ similar to the regression coefficient value of $\beta \mathrm{i}$ ie the loding factor between the $\mathrm{Xi}$ indicator and the formed $\mathrm{Fi}$ factor. If the value of loading factor or lamda value $(\lambda \mathrm{i})$ obtained is greater than or equal to half $(\lambda \mathrm{i} \geq 0.5)$ or can be tested by $\mathrm{t}$ test, and if the variable indicates significant value means $\mathrm{Xi}$ variable or instrument or item is legitimate to serve as member of the factor in question. The steps in conducting confirmatory factor analysis in this study are as follows:

1. Test Prerequisite Analysis

Prior to the process of data analysis usingfactor analysis methods, first performed some prerequisite statistical test are:

a. Normality test

Normality test in this study using One-Sample Kolmogorov-Smirnov Test method, processed using statistical computing software SPSS

b. Linearity Test

This test is used to see if the model specifications used are correct or not. The functions used in an empirical should be linear, squared or cubic. To test the linearity of regression in this study using the function "Compare Mean", processed using SPSS statistical computing software.

\section{Factor Analysis and Hypothesis Testing}

Factor analysis in this study is used to explain the relationship between a number of changes that are mutually independent from one another and to know the dominant factors in explaining a problem. In this study the independent variables analyzed to determine the dominant factor of skill determinants of top and hit skills are height, arm length, arm muscle power, hand eye coordination, balance, and reaction time. Hypothesis testing in this research is done by finding the correlation coefficient of each predictor, the regression equation $\mathrm{Y}$ on each predictor variable, the regression equation Y over all predictor variables together with multiple correlation coefficient. The calculation in testing the hypothesis as follows:

a.Kaiser-Meyer-Olkin and Bartlett's test of sphericity

b.Anti-image correlation test

c. Total variance explained test

d.Communalities or role factors

e.Component matrix (factor compiler dimension)

f. Component score coefficient matrix or factor dimension coefficient factor.

\section{RESULT AND DISCUSSIONS}

Factor analysis in this study was used to compile the factors of a set of variables that were considered feasible to be analyzed. The measurement sub-variable was determined long before the analysis was performed. Anthropometric factors are formed from height, and arm length while the physical factor is formed from arm muscle power, hand eye coordination, balance, and reaction time. The analysis to be used is R Factor to see the correlation between sub-variables, after obtained value from $\mathrm{R}$ factor then conducted Data Reduction to generate new variable covering several variables, from 6 variables become the dominant factor of skill skill determinant and hitting skill will tested whether everything becomes an important variable or only a part of which is feasible to be analyzed and grouped into the main factors. However, before 
analyzing the data using factor analysis method, it is necessary to perform a preliminary analysis test.

The magnitude of the correlation between the independent variables measured has a value between 0 and 1 , to indicate a strong relationship the required KMO-MSA number should be $\geq 0.5$ with an opportunity value (Sig.) Should be $<0.05$. This shows that the collection of variables in this study is significant and can be further processed. Further data will be processed and processed by looking at the magnitude of partial correlation between two variables with still include all variables. This detection is done by looking at Anti Image Correlation resulting in Measure of Sampling Adequacy (MSA) value between 0 to 1 . If MSA $=1$ variable can be predicted without error by other variable, if MSA> 0.5 variable can still be predicted and can be analyzed further and when the MSA $<0,5$ then the variable must be eliminated and can not be further analyzed or removed from the set of other variables.

The results obtained Kaiser-Meyer-Olkin Measure of Sampling Adequacy abbreviated KMO-MSA and Bartlett's Test of Sphericity. The result of KMO-MSA test on 6 tested variables was obtained $0.620>0.5$ while Bartlett's Test of Sphericity showed Approximate Chi-square number of 82.2227 with Degree of Freedom (df) 15 and significance 0.000 . The magnitude of the correlation between the independent measured variable has a value between 0 and 1 , to express a strong relationship the KMO-MSA number should be above 0.5 and with the probability value (Sig.) Should be $<0.05$. This shows that the collection of variables in this study is significant and can be further processed.

TABLE 1. RESULT KMO AND BARTLETT'S TEST ANALYSIS

ANTHROPOMETRIC FACTOR AND PHYSICAL CONDITION DOMINANT DETERMINANTS OVERHEAD THROWS AND BATTING SKILLS IN SOFTBALL

Kaiser-Meyer-Olkin Measure of Sampling Adequacy.

Bartlett's Test of Sphericity Approx. Chi-Square

Df

Sig.

In the Anti Image Matrices correlation table 2, there are two variables that have MSA values below 0.50 each are height $(0.315)$, and reaction time $(0.417)$ which should be reduced again and must be eliminated or eliminated because it is not significant for further test.

The next step is to reduce the variable with factor analysis II by excluding the variable height and reaction time because in the first analysis step both have MSA value below 0.5 which means that factor is not eligible to be included in factor analysis II.

After performing the prerequisite factor analysis test, the next step is to test the advanced factor analysis by reducing or eliminating the factors that have MSA values below 0.5 , ie height $(0.315)$, and reaction time (0.417).
TABLE 2. RESULT ANTI-IMAGE MATRICES CORRELATION

ANALYSIS ANTHROPOMETRIC FACTOR AND PHYSICAL CONDITION DOMINANT DETERMINANTS OVERHEAD THROWS AND BATTING SKILLS IN SOFTBALL.

\begin{tabular}{|c|c|c|c|c|c|c|}
\hline $\begin{array}{l}\text { Anti-image } \\
\text { Correlation }\end{array}$ & Height & $\begin{array}{c}\text { Arm } \\
\text { lenght }\end{array}$ & $\begin{array}{l}\text { Power } \\
\text { arm } \\
\text { muscle }\end{array}$ & $\begin{array}{l}\text { Hand eye } \\
\text { coordination }\end{array}$ & Balance & $\begin{array}{l}\text { Time } \\
\text { reaction }\end{array}$ \\
\hline Height & $.315^{\mathrm{a}}$ & -.494 & -.311 & .021 & .004 & -.117 \\
\hline Arm lenght & -.494 & $.652^{\mathrm{a}}$ & -.173 & .025 & -.064 & .005 \\
\hline $\begin{array}{c}\text { Power arm } \\
\text { muscles }\end{array}$ & -.311 & -.173 & $.685^{a}$ & -.056 & -.096 & .105 \\
\hline $\begin{array}{l}\text { Hand eye } \\
\text { coordination }\end{array}$ & .021 & .025 & -.056 & $.732^{\mathrm{a}}$ & -.180 & -.165 \\
\hline Balance & .004 & -.064 & -.096 & -.180 & $.535^{\mathrm{a}}$ & .247 \\
\hline Time reaction & -.117 & .005 & .105 & -.165 & .247 & $.417^{\mathrm{a}}$ \\
\hline
\end{tabular}

From the table 3, the results of second factor analysis obtained Kaiser-Meyer-Olkin value Sample Sufficiency Measurement (KMO-MSA) and Bartlett Test against Sphericity to 4 exact variables obtained value $0.661>0.5$ while Bartlett's Sphericity Test score shows the number of Estimated Values Chi-square 70,459 with Level of Freedom (df) 6 and significance level 0,000. The magnitude of the difference between the independent variables that have a value between 0 to 1 , to indicate a strong relationship KMO-MSA numbers should be above 0.5 and with the opportunity value (Sig.) Must be $<0.05$. This suggests that the set of variables at this point is significant and may lead to further. From the table above, the results of second factor analysis obtained KaiserMeyer-Olkin value Sample Sufficiency Measurement (KMOMSA) and Bartlett Test against Sphericity to 4 exact variables obtained value 0.661>0.5 while Bartlett's Sphericity Test score shows the number of Estimated Values Chi-square 70,459 with Level of Freedom (df) 6 and significance level 0,000 . The magnitude of the difference between the independent variables that have a value between 0 to 1 , to indicate a strong relationship KMO-MSA numbers should be above 0.5 and with the opportunity value (Sig.) Must be $<0.05$. This suggests that the set of variables at this point is significant and may lead to further.

TABLE 3. RESULT KMO AND BARTLETT'S TEST ANALYSIS ANTHROPOMETRIC FACTOR AND PHYSICAL CONDITION DOMINANT DETERMINANTS OVERHEAD THROWS AND BATTING SKILLS IN SOFTBALL

$\begin{array}{crr}\text { Kaiser-Meyer-Olkin Measure of Sampling Adequacy. } & .661 \\ \text { Bartlett's Test of Sphericity } & \text { Approx. Chi-Square } & 70.459 \\ & \text { Df } & 6 \\ \text { Sig. } & .000\end{array}$

In the table 4 Anti Image Matrices tabulation there is no variable that has MSA value below 0,50 which means that all 
variables can be tested further using extraction process with Principal Component Analysis method that yields value of Communalities.

TABLE 4. RESULT ANTI-IMAGE MATRICES CORRELATION ANALYSIS ANTHROPOMETRI FACTOR AND PHYSICAL CONDITION DOMINANT DETERMINANTS OVERHEAD THROWS AND BATTING SKILLS IN SOFTBALL

\begin{tabular}{ccrrr}
\hline $\begin{array}{c}\text { Anti-image } \\
\text { Correlation }\end{array}$ & $\begin{array}{c}\text { Arm } \\
\text { lenght }\end{array}$ & $\begin{array}{c}\text { Power arm } \\
\text { muscle }\end{array}$ & $\begin{array}{c}\text { Hand eye } \\
\text { coordination }\end{array}$ & Balance \\
\hline $\begin{array}{c}\text { Arm lenght } \\
\text { Power arm } \\
\text { muscles }\end{array}$ &.$- \mathbf{. 6 8 0}^{\mathbf{a}}$ & -.497 & -.174 & -.064 \\
$\begin{array}{c}\text { Hand eye } \\
\text { coordination } \\
\text { Balance }\end{array}$ & -.303 & $\mathbf{. 6 2 3}^{\mathbf{a}}$ & -.174 & -.134 \\
\hline
\end{tabular}

a. Measures of Sampling Adequacy(MSA)

From the table 5 can be seen the initial value and extraction value. The initial value reflects the role or contribution if compiler variable factors individually form these factors, while the results comunalities for each variable is in the extraction column. The extraction value describes the percentage of roles or contributions of each dimension or subvariable of the factor factors individually to the factor. It also means the number in the extraction column shows the percentage of rotated component matrix. From the table above it is known that the role of the largest dimension is the hand eye coordination sub-variable, with a value of 0.701 or $70.1 \%$ and the smallest is arm muscle power with a value of 0.565 or $56.5 \%$. Then to know the donation of each variable on each component, need to do the rotation process that produces Matrix component.

TABLE 5. RESULT COMMUNALITIES ANALYSIS ANTHROPOMETRIC FACTOR AND PHYSICAL CONDITION DOMINANT DETERMINANTS OVERHEAD THROWS AND BATTING SKILLS IN SOFTBALL

\begin{tabular}{ccc}
\hline Variable & Initial & Extraction \\
\hline Arm lenght & 1.000 & .669 \\
Power arm muscles & 1.000 & .565 \\
Hand eye coordination & 1.000 & .701 \\
Balance & 1.000 & .576
\end{tabular}

Extraction Method: Principal Component Analysis.

Based on the results of Component Matrix table 6 . Analysis of anthropometric factors and physical determinants of top-throwing skills, it turns out there is a component factor has a value of $\geq 0.5$ that is the display of arms, arm muscle power, hand eye coordination and balance. This means that the dimensions of the anthropometric and physical factors comprising the variable arm length, arm muscle power, hand eye coordination and balance are members of the anthropometric variable factors and the physical condition of top throwing skill and hitting skills.

TABLE 6 . RESULT COMPONENT MATRIX ${ }^{A}$ ANALYSIS ANTHROPOMETRIC FACTOR AND PHYSICAL CONDITION DOMINANT DETERMINANTS OVERHEAD THROWS AND BATTING SKILLS IN SOFTBALL

\begin{tabular}{cc}
\hline Variable & Component \\
\cline { 2 - 2 } & $\mathbf{1}$ \\
\hline Arm lenght & $\mathbf{. 8 1 8}$ \\
Power arm muscles & .751 \\
Hand eye coordination & $\mathbf{. 8 3 7}$ \\
Balance & .775 \\
\end{tabular}

Extraction Method: Principal Component Analysis.

Hypothesis testing is basically a step to test or find out the truth whether the null hypothesis $(\mathrm{H} 0)$ proposed at a certain level of significance / degree of belief is rejected and the alternative hypothesis ( $\mathrm{Ha}$ ) is accepted, or otherwise the null hypothesis (H0) is accepted and the alternate hypothesis (Ha) is rejected.To know this, in this study hypothesis testing obtained by looking at the value of the results of calculation of Anti-image Matrices Correlation and matrix components. Based on the hypothesis that has been proposed and the calculation of statistical factor analysis has been done then the results of hypothesis testing of this study are:

1. Height determines overhead throws and batting skills in softball

Based on the value of anti-image matrices correlation contained in table 2. factor of arm length has an MSA value of 0.315 or $<0,5$ thus height is not feasible to be a member of the factor and must be eliminated from the follow-up analysis, which means the height of the body is not a member of factor anthropometry determinant of overhead throws andbatting skills in softball (H1 rejected)

2. ArmLength determines overhead throws andbatting skills in softball

Based on the value of anti-image matrices correlation contained in table 2 factor of arm length has a value of MSA of 0.680 or $>0.5$ with the value of communalities in table 4.7 of 0.669 which means that the length of the arm has a percentage of the role of the factor of $66.9 \%$ and the value of the component matrix of 0.818 which means the length of the arm is a member of the anthropometry factor determining the skill of overhead throws andbatting skills in softball ( $\mathrm{H} 2$ accepted)

3. Power arm muscle determines overhead throws andbatting skills in softball

Based on the value of anti-image matrices correlation contained in table 2 power factor arm muscle has a value 
of MSA of 0.623 or $>0.5$ with the value of communalities in table 3 of 0.565 , which means that arm muscle power has a percentage of the role of factors by $56.5 \%$ and the value of the component matrix of 0.751 which means the arm muscle power is a member of the physical conditioning factor determining the skill of overhead throws andbatting skills in softball (H3 accepted)

4. Hand eye coordinationdetermines overhead throws andbatting skills in softball

Based on the value of anti-image matrices correlation contained in table 2 hand eye coordination factor has a value of MSA of 0.741 or> 0.5 with the value of communalities in table 3 of 0.701 which means hand eye coordination has a percentage of the role of the factor of $70.1 \%$ and the value of component matrix of 0.837 which means hand eye coordination is a member of the anthropometry factor determinant of overhead throws andbatting skills in softball(H4 accepted)

5. Balance determines overhead throws andbatting skills in softball

Based on the value of anti-image matrices correlation contained in table 2 balance factor has an MSA value of 0.660 or $>0.5$ with the value of communalities in table 3 of 0.576 , which means the balance has a percentage of the role of the factor of $7.6 \%$ and the value of component matrix of 0.575 or $>0.5$ which means the balance is a member of the physical condition factor determining the skill of overhead throws andbatting skills in softball (H5 accepted)

6. Reaction time determines overhead throws andbatting skills in softball

Based on the value of anti-image matrices correlation contained in Table 2 the reaction time factor has an MSA value of 0.417 or $<0.5$ thus the reaction time is not feasible to be a member of the factor and must be eliminated from further analysis, which means the reaction time is not a member of a factor anthropometry determinant of overhead throws andbatting skills in softball (H6 rejected).

\section{CONCLUSION}

Based on the results of the analysis, all of the anthropometry factors and the dominant physical conditions that became the determinants and not on the skills of overhead throw and batting in softball can be summarized as follows: The anthropometric factors and the dominant physical condition determine the skills of the overhead throw and batting skills on the softball game arm length with component value matrix 0,818 , arm muscle power with component value matrix 0,751 , hand eye coordination with value 0,837 and balance with component value matrix 0,775 . While the factors that do not determine the height and reaction time

\section{REFERENCES}

[1] Gudono, 2012, "Multivariate data analysis," Yogyakarta: BPFE.

[2] Sajoto. M, 1988, "Enhancement and coaching physical condition strength in sport," Semarang: Offset, Effhar \& Dahara Prize, [pp. 11, 88, 99].

[3] Siswandari, 2011, "Basic computer statistics," Surakarta: LPP UNS and UNS Press, p. 156.

[4] Utami. H. P, 2008, "Game of kasti and its kind," Jakarta: Ganeca Exact, p. 15.

[5] Widyastuti. E, 2013, "Softball and baseball," Semarang: Aneka Ilmu, p. 1. 